\title{
Synthesis and Properties of New Dihydroquercetin Derivatives
}

\author{
Alexander M. Koroteev, Tatyana S. Kukhareva, Mikhail P. Koroteev, Garry Z. Kaziev, Sergey E. Mosyurov and \\ Andrey T. Teleshev \\ Chemical Department, Moscow State Pedagogical University, Moscow 119021, Russia
}

\begin{abstract}
This paper is to analyze the latest data on synthesis, structure, chemical and biological properties of flavonoid dihydroquercetin (taxifolin). Complexes including DHQ (dihydroquercetin) into cyclodextrins were obtained. These supramolecular representatives are characterized by high water-solubility, good permeability through biomembranes, prolonged action in the organism and stability while being transported in bloodflow. The use of DHQ in complex with $\beta$-cyclodextrin is more promising from the medical point of view than the use of pure DHQ. Total and partial acidylation of DHQ with acid chlorides of aliphatic, aromatic, and heterocyclic carboxylic acids, as well as selective phosphorylation with acid derivatives of trivalent phosphorus (with amides and amidethers of phosphorous acid), and aminomethylation were carried out. DHQ freely undergoes Mannich Reaction with formaldehyde and amines of various structures. The products of the reaction are isolated from the reaction mix with good yield. Isolated aminomethylated derivatives have neurotropic and antiproliferative action. The structure of all synthesized compounds was proved with the help of modern methods of analysis: spectroscopy NMR $\left({ }^{1} \mathrm{H},{ }^{13} \mathrm{C}\right)$ and XRS. Biological activity of dihydroquercetin modified derivatives was studied. It was found out that some of them are characterized by high cytotoxic, antitumour, and antioxidant biological activity. The inclusion complexes of dihydroquercetin and cyclodextrin were obtained. Acylation, phosphorylation and aminomethylation of dihydroquercetin was performed. The biological activity of obtained compounds was studied.
\end{abstract}

Key words: Flavonoids, dihydroquercetin, cyclodextrin, acylation, phosphorylation, aminomethylation, biological activity.

\section{Introduction}

Flavonoids constitute a large group of natural compounds of the same molecular skeleton which consists of three six-membered rings, two of them being aromatic and the third having, as a rule, a pyranoidal nature (Fig. 1).

The difference lies only in the number and position of oxygen-containing substituents (the level of oxidation). Ring A is usually hydroxylated in positions situated at intervals of one component (5 and 7), while in ring $\mathrm{B}$ the adjoining positions are usually hydroxylated (primarily 3' and 4').This type of hydroxylation reflects different biosynthetic origin of the two above-mentioned rings. In nature flavonoids are contained only in plants, there is no information

Corresponding author: Garry Z. Kaziev, professor, research fields: coordination chemistry, chemistry of the heteropoly compounds and biological active substances chemistry. E-mail: gkaziev@mail.ru. about their animal production. Many members of this class of natural compounds are richly colored and that is why they are vitally important for plants ecology, making their flowers and fruit attractive for bees and birds, respectively. Colorless flavonoids are also likely to be met. It is notable that though flavonoids are widely met in superior plants they are lacking in such inferior forms as lichen and moss. Fungi and bacteria give no evidence yet of being able to produce flavonoids. The variety of structures can also be explained by the formation of glycosides, as well as of methoxy- and methylenedioxy-groups at later stages of flavonoids biosynthesis. In nature flavonoids are frequently connected with such monosaccharides as glucose and rhamnose, and with some disaccharides, for example, with rutinose.

Flavonoid compounds have aroused considerable interest due to the fact that in 1936 A. Szent-Gyorgyi and a group of German scientists showed that a number 
<smiles>O=C1c2c(O)cc(O)cc2OC(c2ccc(O)c(O)c2)C1O</smiles>

Fig. 1 Taxifolin (Dihydroquercetin) (atoms numeration).

of flavonoids possess a pronounced biological activity characteristic vitamins. They partially relieve the degree of vitamin $\mathrm{C}$ deficiency, decrease vascular capillary permeability and fragility. This resulted in calling flavonoid compounds Vitamin $\mathrm{P}$ ("permeability"). Catechine, quercetin (yellow flower flavonone) and its glycoside rutin are typical representatives of substances with this type of activity. They are widely used in treating hypo- and avitaminosis, as well as many vascular diaeases, hypertensia, measles, scarlet fever, European fever, radiation sickness, etc.

Dihydroquercetin (1) (taxifolin) (subsequently referred to as DHQ) [1-2] was extracted from Douglas-fir bark and described at the end of 1940s. It is a quercetin analogue, hydrated in positions 2 and 3, having the same P-vitamin activity. Moreover, it possesses a number of other important and useful properties, not characteristic of the majority of flavonoids, such as:

(1) Inactivation of cytotoxic substances [3];

(2) Antidiabetic activity [4];

(3) Termination of free radicals and peroxidation prevention $[5,6]$;

(4) Reduction of lipoprotein content in liver and blood plasma [7];

(5) Antitumour effect [8];

(6) Antimutagene activity ]9];

(7) Antiradiation activity [10];

(8) Immunoregulatory (antiallergic) and anti-inflammatory activity [11, 12].

(9) Normalizing effect on cell fermentative systems
[13];

(10) Pain-relieving and anti-edema action [14];

(11) Low mutagenic activitytoxicity $[15,16]$;

(12) Antiviral activity [17].

In 2002-2004 we developed and patented simple and accessible methods of DHQ extraction from Siberian larch-tree waste wood (but-log portions and stumps) $[18,19]$. The substance was defined with the help of modern physical-chemical methods NMR and XRS.

X-ray spectral analysis (Fig. 2) showed that the obtained product is optically clear (space group C2). Complete identity of the substance with pharmacopeial drug is proved.

Possessing unique biological properties DHQ has one drawback-poor solubility in water at normal temperature. This fact makes it difficult to prepare its injection forms. Poor solubility of DHQ in water and physiological solution also prevents its uptake by the organism if it is taken orally.

\section{Water-Soluble Dihydroquercetin}

In this connection we developed a method of obtaining formerly unknown DHQ adducts. For this purpose complexes including DHQ into $\alpha$ - and $\beta$-cyclodextrins were synthesized. These supramolecular
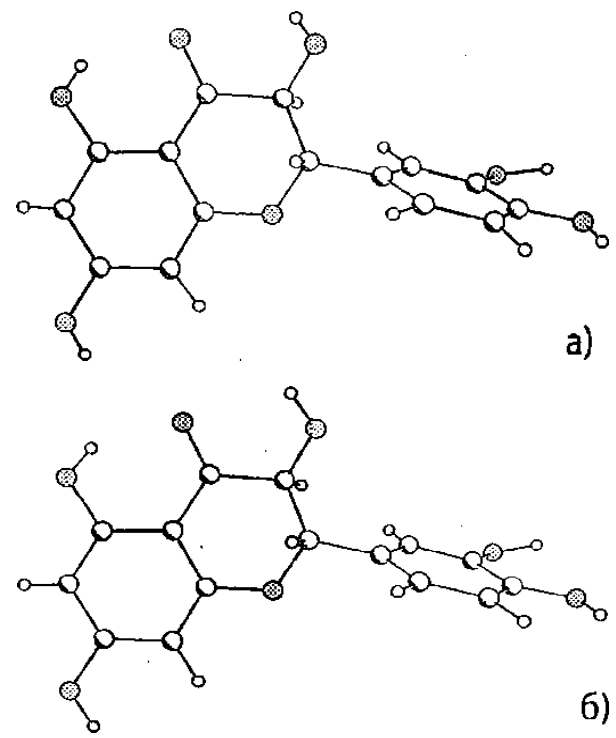

Fig. 2 DHQ molecule: (a) pharmacopeial drug (from water-ethanolic solution); (b) obtained by a new method of purification (from deionized water). 
representatives are characterized by high water-solubility, prolonged action in the organism and stability while being transported in bloodflow. The process of obtaining DHQ complex with $\beta$ -cyclodextrin takes place according to the following scheme:

$$
\begin{gathered}
\mathrm{C}_{15} \mathrm{H}_{12} \mathrm{O}_{7} * 2,5 \mathrm{H}_{2} \mathrm{O}+\mathrm{C}_{42} \mathrm{H}_{70} \mathrm{O}_{35} * 6 \mathrm{H}_{2} \mathrm{O} \rightarrow \\
\text { Taxifolin (1) } \quad \beta \text {-cyclodextrin } \\
\mathrm{C}_{57} \mathrm{H}_{82} \mathrm{O}_{42} * \mathrm{nH}_{2} \mathrm{O}
\end{gathered}
$$

Inclusion complex (2)

It was shown that solubility in water at $200{ }^{\circ} \mathrm{C}$ of the obtained supramolecular compound with the composition DHQ: $\beta$-cyclodextrin 1:1 as compared with free DHQ $(0.3 \mathrm{~g} / \mathrm{L})$ and with free $\beta$-cyclodextrin $(18.5 \mathrm{~g} / \mathrm{L})$ is noticeably higher and constitutes $53.2 \mathrm{~g} / \mathrm{L}$.

The obtained inclusion complexes were examined as to the comparative with free DHQ speed of diffusion (penetration) through the bilayer of standard two-layer liposomes from egg lecithin which is a good model of cell membranes. It is found out that "unincluded" (individual) DHQ binds to membranes and practically does not penetrate into the cells. As for "included" taxifolin, it enters the cells in measured amount over a period of several hours, i.e. it is a product of prolonged action.

The best means to investigate DHQ permeability through biomembranes is to test its content in blood after its oral intake as a food additive. In 2.5-3 hours after the intake of pure DHQ and its derivatives $\alpha$-cyclodextrin + DHQ and $\beta$-cyclodextrin + DHQ, DHQ was found in rats blood plasma only in case of using the product $\beta$-cyclodextrin + DHQ. Thus, we can assert that the intake of this preparation secured effective transportation of DHQ in rats' bloodflow.

In case of inletting pure unbound DHQ into rats' stomachs it accumulates in their livers and at high concentrations may cause allergy and some other kinds of toxication. At the same time DHQ in complex with $\beta$-cyclodextrin does not accumulate in liver and causes no side toxic effect.

The structure of encapsulated DHQ (2) was studied using XPS. The result of X-ray diffraction analysis of the monocrystal inclusion complex confirms its composition DHQ: $\beta$-cyclodextrin 1:1. The plane projection of its structure is given in Picture 3.

Thus, we have found out a new way of obtaining formerly unknown inclusion complexes of flavonoid DHQ with $\alpha$ - and $\beta$-cyclodextrins through interconnection of a guest and a host.

It has been demonstrated that the use of DHQ in complex with $\beta$-cyclodextrin is more promising from the medical point of view than the use of pure DHQ (Fig. 3). This investigation is patented-Patent of the Russian Federation \# 2396077 in 2010 [20].

\section{Modified Derivatives of Dihydroquercetin}

\subsection{Synthesis of Dihydroquercetin Compound Esters}

The earliest investigation in the sphere of obtaining taxifolin compound esters was its acetylization. The treatment of DHQ with acetic oxide with high yield resulted in the synthesis of acetyl derivatives of DHQ: tetraacetate (3) and pentaacetate (4) of dihydroquercetin [21]. The detailed structure of acetates structure was carried out with the help of UV-, IR-, NMR-spectroscopy [21, 22]. The means of obtaining acetates were different due to the difference in the conditions of carrying out reactions, because to

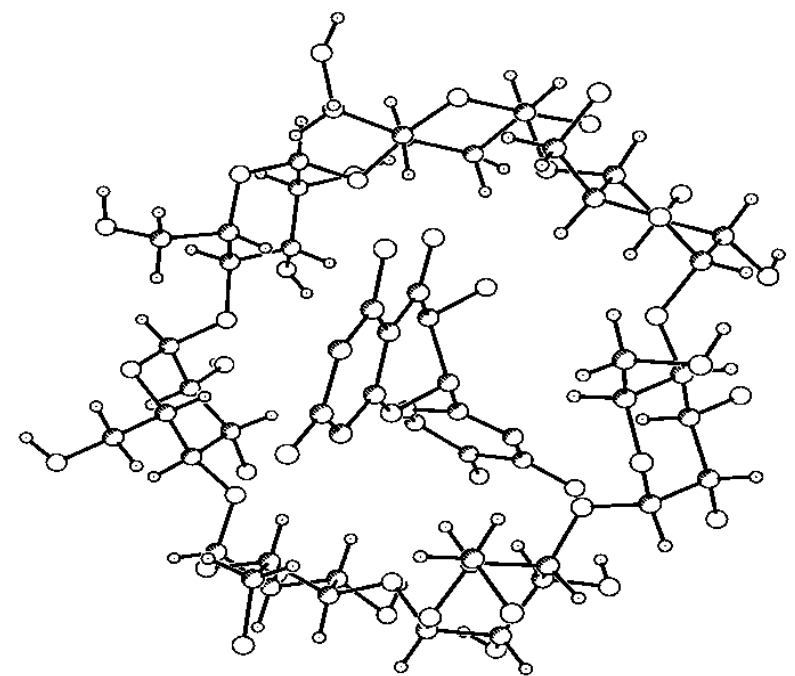

Fig. 3 The plane projection of DHQ inclusion complex in $\beta$-cyclodextrin (2). 
get pentaacetate of dihydroquercetin you need more rigid conditions promoting hydrogen bond rupture, in particular, higher temperature $\left(120^{\circ} \mathrm{C}\right)$ and a catalyst (Fig. 4).

At present the structure (3) is studied with the help of XRS method (Fig. 5) [23]. Geometrical characteristics of the molecule after acetylization as compared with those for the initial flavonoid are practically not changed. In the molecule of tetraacetate of dihydroquercetin the hydrogen bond between the oxygen atom of the carbonyl group and the hydrogen atom of the hydroxyl group in the fifth position is preserved. The turn angle of the aromatic ring $\mathrm{B}$ is practically not changed as well.

Later other authors using the same reagents found the conditions of disengagement from the reaction mix with the help of chromatographic method of triacetate of DHQ - 3',4',7-triacetate of dihydroquercetin (5) [23].

More complex acyl derivatives of DHQ were obtained in our laboratory by treating the flavonoid with a number of mixed carboxylic acid anhydrides. In doing so we chose acids which are synthetic predecessors of medicinal products: benzoic, acetylsalicylic,nicotinic, $n$-nitrobenzoic, phenylacetic, palmic, and trimethylacetic. Peracetic derivatives of DHQ were obtained by treating DHQ with $10 \%$ excess of acid chlorides of the above-enumerated aromatic and aliphatic acids at room temperature or upon the application of low-level heating $\left(40-60{ }^{\circ} \mathrm{C}\right)$ according

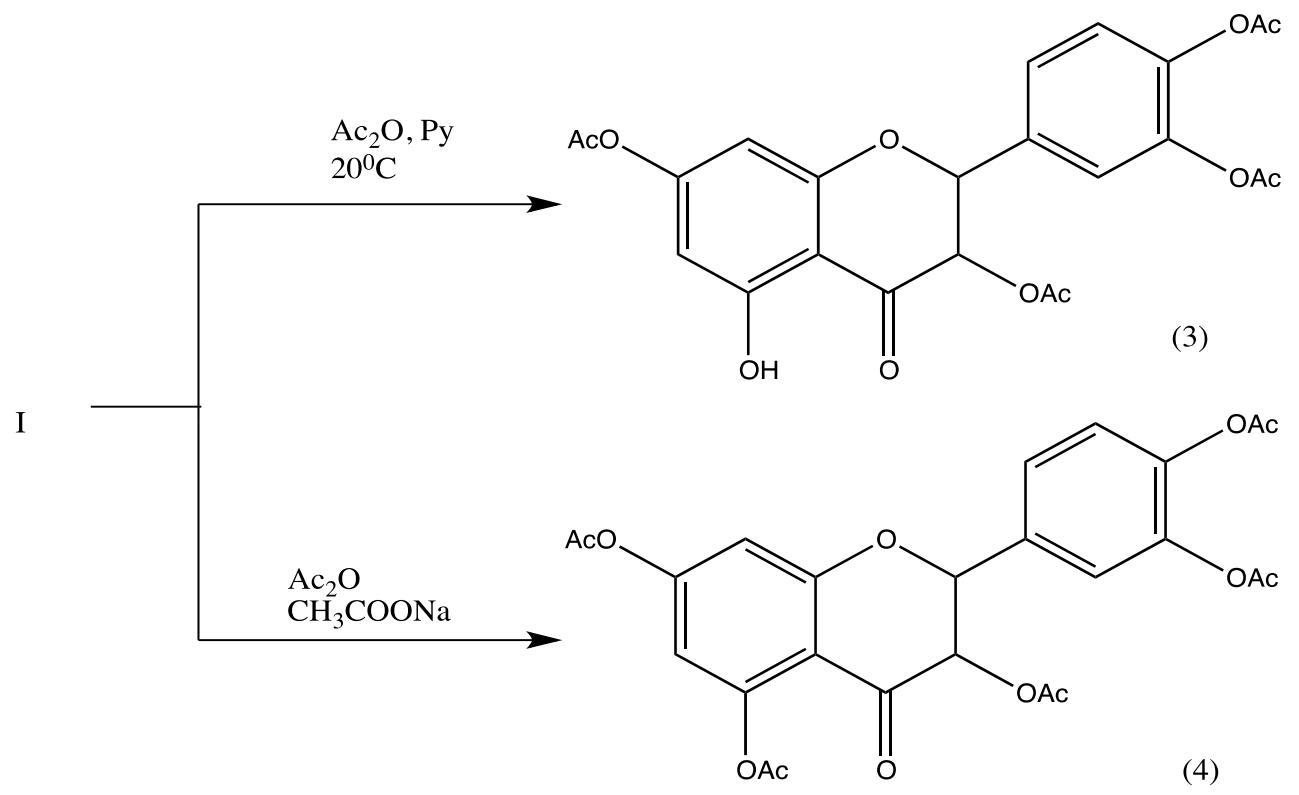

Fig. 4 Derivatives of DHQ - tetraacetate (3) and pentaacetate (4) of dihydroquercetin.

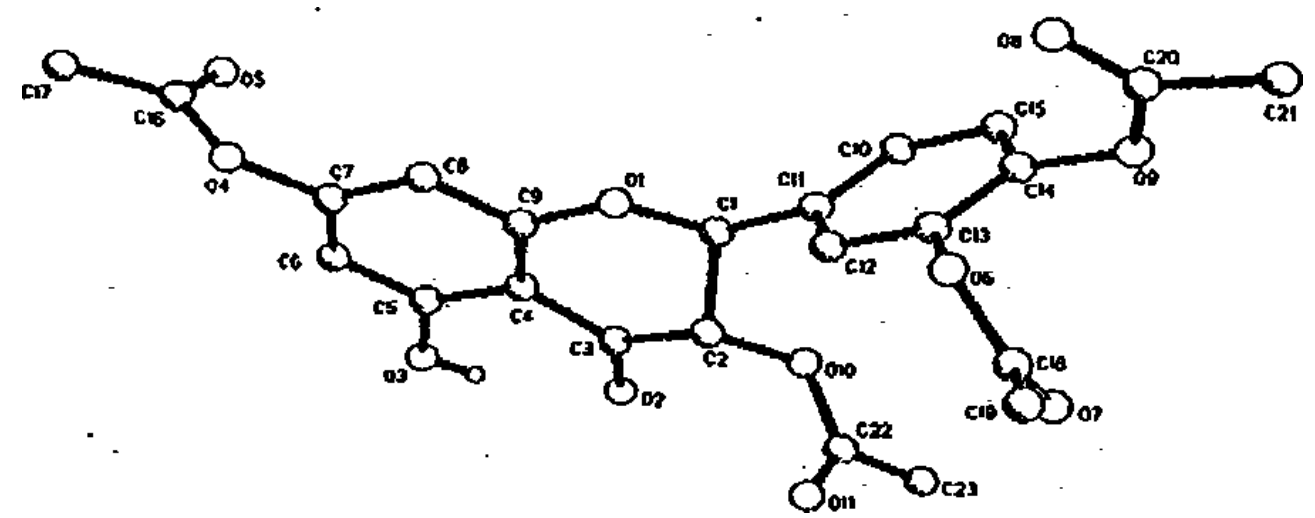

Fig. 5 Independent molecule of 3,3',4',5,7-tetraacetyl-2,3- dihydroquercetin (3). 
<smiles>[R]C(=O)Oc1cc(OC([R])=O)c2c(c1)OC(c1ccc(OC([R])=O)c(OC([R])=O)c1)C(OC([R])=O)C2=O</smiles><smiles>Cc1ccccc1</smiles>

(6a)<smiles>CC(=O)Oc1ccccc1C</smiles>

(6b)<smiles>Cc1cccnc1</smiles>

(7)<smiles>CC(C)(C)C</smiles><smiles>Cc1ccc([N+](=O)[O-])cc1</smiles>

(8)<smiles>CCc1ccccc1</smiles>

(9)<smiles>C[AsH2-]</smiles>

(10)

Fig. 6 Synthesis of DHQ peracetic derivatives (6-11).

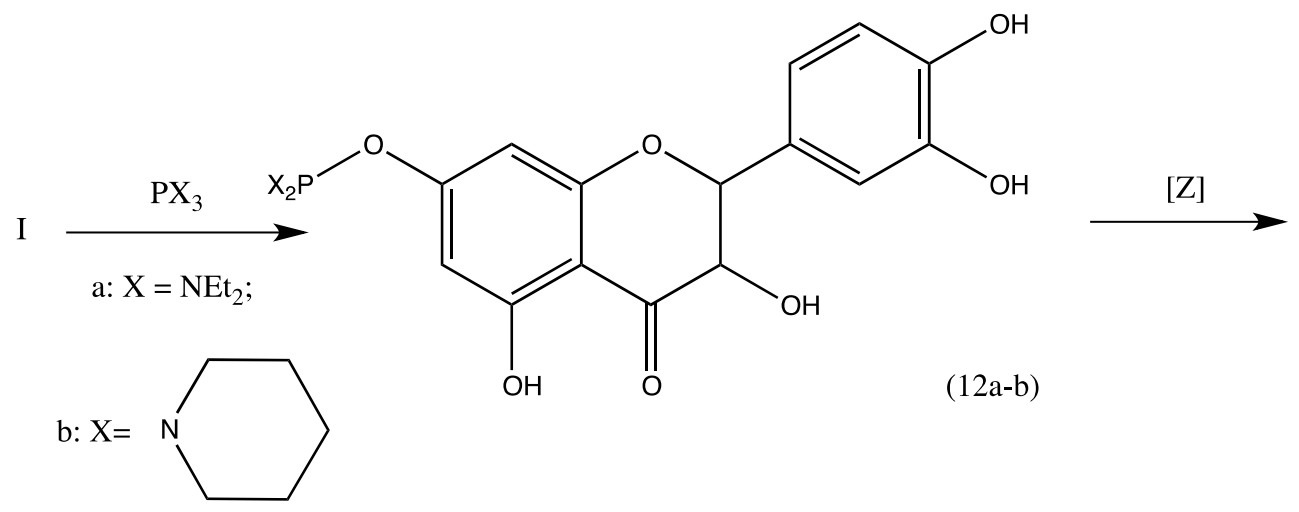<smiles>[Z][Y20]Oc1cc(O)c2c(c1)OC(c1ccc(O)c(O)c1)C(O)C2=O</smiles>

Fig. 7 Synthesis of DHQ phosphoric derivatives. 
to the following scheme (Fig. 6).

The following compound ethers were isolated and defined:

3,3',4',5,7-pentabenzoyl-2,3-dihydroquercetin (6a), 3,3',4',5,7-pentaacetylsalicyl-2,3- dihydroquercetin (6b), 3,3',4',5,7-pentanicotinoyl-2,3-dihydroquercetin (7),

3,3',4',5,7-penta-n-nitrobenzoyl-2,3-dihydroquercet in $(8)$,

3,3',4',5,7-pentaphenylacetyl-2,3-dihydroquercetin

(9), 3,3',4',5,7-pentapalmitoyl-2,3-dihydroquercetin (10),

3,3',4',5,7-pentatrimethylacetyl-2,3-dihydroquercetin (11),

Compounds yields depending on the acid residue $\mathrm{R}$ constituted $61 \%-82 \%$. As it turned out that after introduction of acyl groups into DHQ molecule the latter can be regarded as a potential biological structure which substantially extends the sphere of biological activity of this flavonoid.The conducted biological tests proved this (See Part 3).

The structure of all products, formerly unknown, is proved with the help of spectroscopy $\mathrm{NMR}{ }^{1} \mathrm{H}$ and ${ }^{13} \mathrm{C}$, and confirmed by the data of element analysis [24].

\subsection{Synthesis of Dihydroquercetin Phosphoric Derivatives}

The study of DHQ phosphorylation reactions has apart from scientific interest its practical significance, because as a result of interaction new organic compounds are formed. Potentially they can have antioxidant, anti-inflammatory, and antitumour activity. We studied the possibility of DHQ phosphorylation with various derivatives of phosphorous acid (chlorine anhydrites, amidophosphites) and phosphoric acid chlorine anhydrites.

3.2.1 Phosphorylation with phosphorous acid triamides

Three active reaction centers are included into the molecules of phosphotriamides. Due to this fact there exists a wide range of peculiar ways to phosphorylate
DHQ with these reagents.

Phosphorylation of DHQ with hexamethyltriamide of phosphorous acid in the ratio of 1:1 was carried out in dioxin on cooling. On completion of the process several signals with chemical shifts in the range 149-151 and 133-134 ppm in $\mathrm{NMR}^{31} \mathrm{P}$ spectrum of the reaction mix were observed. According to these data phosphorylation takes place non-selectively in several hydroxyl groups.

Thus, hexamethyltriamide of phosphorous acid seems to be a too active reagent for selective phosphorylation of DHQ.

Taking this into consideration we decided to use less active phosphotriamides - hexaethyltriamide and tripiperidide of phosphorous acid [25].

The production of DHQ tetraethyldiamide- and dipiperidylphosphites in the pure state was the result of complex work on selecting the conditions for conducting regioselective process. Phosphorylation was carried out at lower temperature $\left(10{ }^{\circ} \mathrm{C}\right)$, high dilution of the reaction mix $\left(\mathrm{C}_{\mathrm{DHQ}} 0.01 \mathrm{M}\right)$, and very slow addition of the reagent to the solution of DHQ (Fig. 7).

Next we obtained amidophosphites of dihydroquercetin (12a-b) without isolation from the reaction mix underwent sulfurization yielding the products (13a-b) and selenization yielding the products (14a-b), which were purified with column chromatography on silica gel. They were powders of light-yellow color. Their structure is proved with the help of spectroscopy $\mathrm{NMR}{ }^{1} \mathrm{H}$ and ${ }^{13} \mathrm{C}$, and their composition is confirmed by the data of element analysis. All the necessary signals of carbon protons and atoms of flavonoid matrix and their substitutes are present in the spectra (Fig. 8).

3.2.2 Phosphorylation with phosphorous acid diamidethers

To continue the investigation in the sphere of flavonoids phosphoric derivatives we studied DHQ phosphorylation with phosphorous acid diamidethers (Fig. 9). 


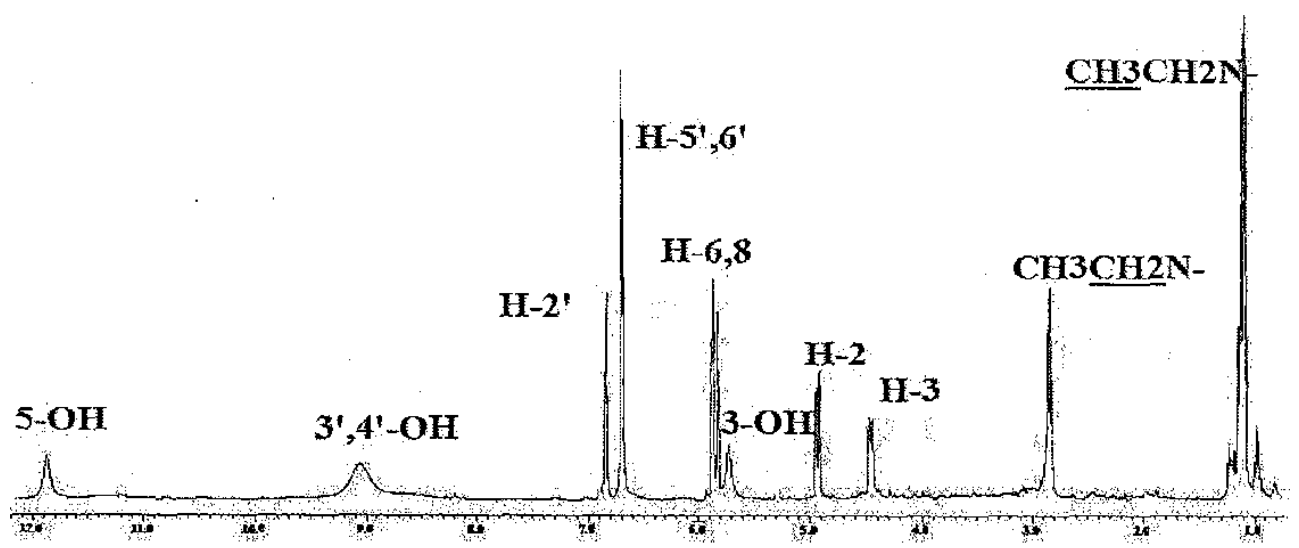

Fig. 8 DHQ 7-tetraethyldiamidethionphosphate NMR ${ }^{1} \mathrm{H}$ spectrum.

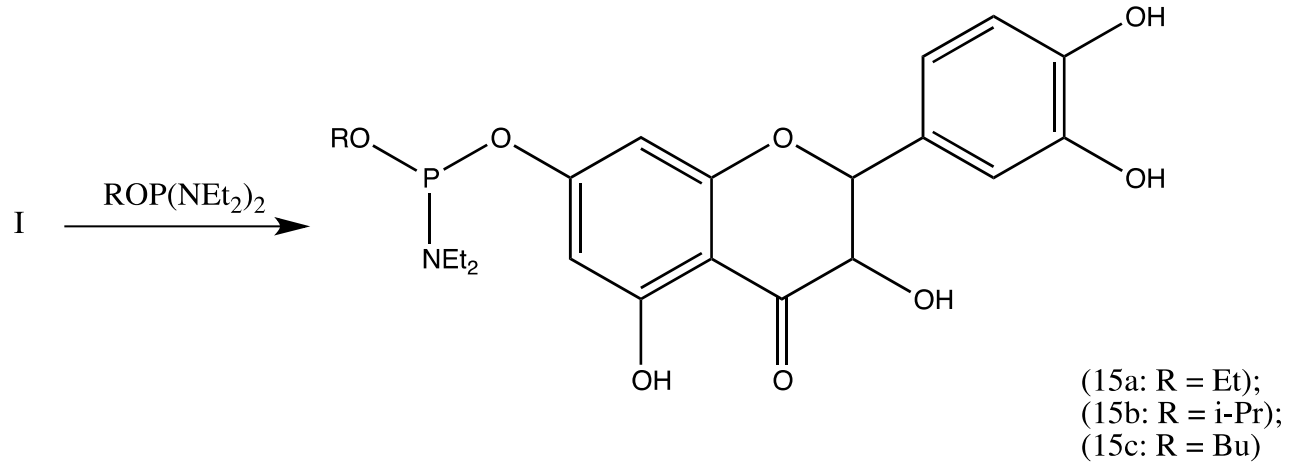

Fig. 9 DHQ phosphorylation with phosphorous acid diamidethers.<smiles>[R6]P(N=C)Oc1cc(O)c2c(c1)OC(c1ccc(O)c(O)c1)C(O)C2=O</smiles><smiles>[Z][PH]([R])(N=CC)Oc1cc(O)c2c(c1)OC(c1ccc(O)c(O)c1)C(O)C2=O</smiles>

Fig. 10 Obtaining thion- and selenphosphate derivatives of DHQ.

Diethyl, butyl and isopropyl ethers of phosphorous acid were used as phosphorylizing reagents [21].

Singlets with chemical shifts 144.9 ppm (15a), 146.4ppm (15b), and $145.5 \mathrm{ppm}$ (15c) were observed in $\mathrm{NMR}^{31} \mathrm{P}$ spectra of the reaction mix.

Intermediate derivatives of trivalent phosphorus 
generated on the base of DHQ (15a-c) without isolation from the reaction mix were transferred into the corresponding thion- and selenphosphatic derivatives (16a-c) and (17a-c) (Fig. 10). Singlets with proper chemical shifts were observed in $\mathrm{NMR}^{31} \mathrm{P}$ spectra. The formation of only one stereoisomer, not of their mixture, can be explained by a large content of the substitute and, as a result, by a considerable difference of energetic levels of two possible stereoisomers. The compounds were purified with column chromatography.

The structure of the obtained compounds was unambiguously proved with the help of spectroscopy NMR ${ }^{1} \mathrm{H}$, and their composition is confirmed by the data of element analysis. All the necessary signals of protons of flavonoid molecule and their substitutes were present in the spectrum.

3.2.3 Phosphorylation with phosphorous acid monoamidediethers

To continue the investigation the possibility of DHQ phosphorylation with a less active type of phosphorylizing reagents-phosphorous acid monoamidediethers was studied.

Thus, phosphorylation with equimolar amount of neopentylenediethylamidephosphite in dioxin on cooling is going on slowly enough - nearly 36 hours, during which a singlet with a chemical shift $115.4 \mathrm{ppm}$ in NMR ${ }^{31} \mathrm{H}$ was observed (Fig. 11).<smiles>CCN1CCC(C)(C)CC1</smiles>

(19)

Fig. 11 The first stage of DHQ phosphorylation with monoamidediethers of phosphorous acid.<smiles>CC1(C)CCP(Oc2cc(O)c3c(c2)OC(c2ccc(O)c(O)c2)C(O)C3=O)CC1</smiles>

(19)<smiles>CC1(C)CCP(=O)(Oc2cc(O)c3c(c2)OC(c2ccc(O)c(O)c2)C(O)C3=O)CC1</smiles>

$(120 \mathrm{a}: \mathrm{Z}=\mathrm{S})$;

Fig. 12 The second stage - interaction with sulfur and selenium. 


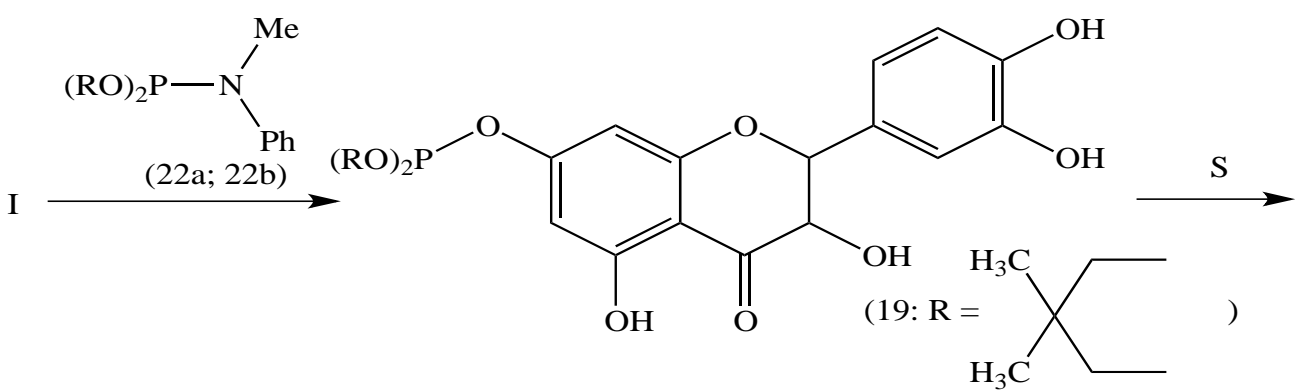

$(21: \mathrm{R}=\mathrm{Et})$<smiles>[R20][R20](=O)Oc1cc(O)c2c(c1)OC(c1ccc(O)c(O)c1)C(O)C2=O</smiles>

$(23: \mathrm{R}=\mathrm{Et})$

Fig. 13 The general scheme of obtaining the final product.<smiles>[R20]Cc1c(O)cc2c(c1O)C(=O)C(O)C(c1ccc(O)c(O)c1)O2</smiles>

(24: $\left.\mathrm{R}=\mathrm{R}^{\prime}=i-\mathrm{Pr}\right)$;

(25: $\mathrm{R}=\mathrm{Me}, \mathrm{R}^{\prime}=\mathrm{CH}_{2} \mathrm{C}_{6} \mathrm{H}_{5}$ )<smiles>[R2]NCc1c(O)c(CN[R2])c2c(c1O)C(=O)C(O)C(c1ccc(O)c(O)c1)O2</smiles>

(26: $\mathrm{R}=\mathrm{R}^{\prime}=i$-Pr);

(27: $\mathrm{R}=\mathrm{Me}, \mathrm{R}^{\prime}=\mathrm{CH}_{2} \mathrm{C}_{6} \mathrm{H}_{5}$ )

Fig. 14 Synthesis of DHQ aminomethylated derivatives.

Holding the reaction mix at $40{ }^{\circ} \mathrm{C}$ allowed to reduce the time of reaction to 7 hours. The increase of the process temperature to $60{ }^{\circ} \mathrm{C}$ was accompanied by phosphorylation of alcohol hydroxyl group which was proved by the appearing of a new singlet in phosphorus spectrum with a chemical shift $122.3 \mathrm{ppm}$. The use of 
higher temperature resulted in destructive processes.

The substance (19) from the reaction mix was not isolated due to its lability, it was immediately introduced into interaction with sulfur and selenium (12) (Fig. 12).

After sulfurization and selenization which were carried out during 3 hours and on heating up to $40{ }^{\circ} \mathrm{C}$, singlets with chemical shifts 53.9 ppm (20a) and 66.3 ppm (20b) were traced in the reaction mix.

Synthesis with the use of N-methyl-, $\mathrm{N}$-phenyldiethylamidephosphites was carried out in a similar way.

On sulfur addition the desired product (20a) was isolated with column chromatography ( $45 \%$ yield).

The structure of the obtained thionphosphates (20a) and (23) (Fig. 13) was proved with the help of spectroscopy NMR ${ }^{1} \mathrm{H}$ and ${ }^{31} \mathrm{P}$. Singlets with chemical shifts 53.9 and 61.2, corr3espondingly, were traced in phosphorus spectra. In NMR ${ }^{1} \mathrm{H}$ spectra there was no signal from proton in position 7 of the flavonoid molecule. All the necessary signals of protons substitutes were observed.

\subsection{Synthesis of Dihydroquercetin Aminomethylated Derivatives}

DHQ freely undergoes Mannich Reaction with formaldehyde and amines of various structures. Our investigation has shown that the products of the reaction are isolated from the reaction mix spontaneously with good yield (Fig. 14).

Many of the isolated substances have a high biological activity, for example, they have neurotropic [26] and antiproliferative [27] action.

\section{Biological Activity of Dihydroquercetin Modified Derivatives}

\subsection{Biological Activity of Dihydroquercetin Peracilic derivatives}

Pharmacological activity of some of the synthesized DHQ peracilic derivatives was investigated at the Chair of molecular pharmacology and radiobiology of the Medical-Biological Department of the Russian State Medical University (Moscow) [27].

Thus, we studied the impact of pentabenzoate (6a), penta-n-nitrobenzoate (8), pentaacetylsalicylate $(6 \mathrm{~b})$, and pentanicotinate of dihydroquercetin (7) on the vitality of normal and tumour cells on the culture of newborn rats skin fibroplast and on the culture of MCF-7 cells (human breast cancer). The impact of the preparations on cell growth was defined by microcolorimetric method using MTT assay [28], which is based on the ability of living cells dehydroganases to restore the colorless form of tetrazolium salt (3-[4,5-dimethylthiazole 2-yl]-2,5 diphenyltetrazolium bromide, MTT-reagent) with the formation of blue formazan crystals soluble in dimethylsulfoxide. Optical absorption of the soluted in dimethylsulfoxide formazan is proportional to the number of living cells in the sample. The inhibition of cells growth in the sample was defined according to the formula

$\mathrm{IC} \%=\left(1-\mathrm{N}_{\mathrm{o}} / \mathrm{N}_{\mathrm{k}}\right) \cdot 100$.

The compound was considered active if the concentration 100 microns caused cells growth inhibition $>50 \%$.

The investigation showed the dependence of cytotoxic effect on the concentration of the studied compound and on its chemical structure. Penta-n-nitrobenzoate, pentaacetylsalicylate, and pentanicotinate of dihydroquercetin showed the highest activity (Tables 1 and 2). Pentanicotinate of dihydroquercetin in concentration $1 \mathrm{mg} / \mathrm{ml}$ showed the most apparent cytostatic action.

To study the antioxidant activity of the derivatives the chemiluminescence method on the model of rats brain homogenate was used $[5 ; 29]$. For the induction of lipids peroxidation (POL) ions of divalent ferrum were added into the system. This initiated POL process which was accompanied with chemiluminescence.

Our investigation has shown that the studied compounds are not similar in their impact on POL processes in rats brain homogenate. Dihydroquercetin 
Table 1 Impact of DHQ derivatives on MCF-7 cells vitality.

\begin{tabular}{llll}
\hline \multirow{2}{*}{ Test compounds } & \multicolumn{2}{c}{$\mathrm{C}, \mathrm{mg} / \mathrm{mL}$} \\
\cline { 2 - 4 } & 1,0 & 0,1 & 0,01 \\
\hline Penta- $n$-nitrobenzoate of dihydroquercetin (8) & $40 \%$ & $91 \%$ & $96 \%$ \\
Pentaacetylsalicylate of dihydroquercetin (6b) & $65 \%$ & $90 \%$ & $105 \%$ \\
Pentanicotinate of dihydroquercetin (7) & $14 \%$ & $98 \%$ & $97 \%$ \\
\hline
\end{tabular}

Note: $\mathrm{C}$-concentration, $\%$ - per cent of viable cells.

Table 2 Impact of DHQ derivatives on rats fibroplast vitality.

\begin{tabular}{llll}
\hline \multirow{2}{*}{ Test compounds } & \multicolumn{2}{c}{$\mathrm{C}, \mathrm{mg} / \mathrm{mL}$} \\
\cline { 2 - 4 } & 1,0 & 0,1 & 0,01 \\
\hline Penta- $n$-nitrobenzoate of dihydroquercetin (8) & $26 \%$ & $85 \%$ & $110 \%$ \\
Pentaacetylsalicylate of dihydroquercetin (6b) & $70 \%$ & $98 \%$ & $102 \%$ \\
Pentanicotinate of dihydroquercetin (7) & $2 \%$ & $88 \%$ & $104 \%$ \\
\hline
\end{tabular}

Note: $\mathrm{C}$-concentration, $\%$ - per cent of viable cells.

Table 3 Impact of DHQ derivatives on the amplitude of slow flare of $\mathrm{Fe}^{2+-}$ induced chemiluminescence curve of rats brain homogenate ( $\%$ as compared with control); solution-DMSO.

\begin{tabular}{ll}
\hline Group & $\mathrm{H}$ \\
\hline Dihydroquercetin (1) & 100 \\
Pentabenzoate of dihydroquercetin (6a) & $13 \pm 8$ \\
Penta- $n$-nitrobenzoate of dihydroquercetin (8) & $20 \pm 9$ \\
Pentaacetylsalicylate of dihydroquercetin (6b) & $9 \pm 5$ \\
Pentanicotinate of dihydroquercetin (7) & $60 \pm 5$ \\
\hline
\end{tabular}

Note: $\mathrm{H}$ - the amplitude of slow flare of chemiluminescence; dihydroquercetin derivatives concentration $10^{-4} \mathrm{M}$.

and pentanicotinate of dihydroquercetin have the highest inhibiting activity, they reduced the amplitude of slow flare by $60 \%$ (Table 3 ).

Besides, newly-synthesized compounds: 3,3,4,5,7-pentaacetylsalicyl-2,3- dihydroquercetin (6b), 3,3,4,5,7-penta- $n$-nitrobenzoyl-2,3-dihydroquercetin (8), and 3,3,4,5,7-pentanicotinate-2,3-dihydroquercetin (7), were tested for their anti-inflammatory activity.

We have taken a burn injury as a model for investigating anti-inflammatory properties of these compounds because it is characterized by a high intensity of oxidative stress and inflammatory reaction with animals.

The studied preparations were used as applications on burn surfaces on the skin of laboratory mice in certain concentration. After a period of treatment the animals were tested on the factors of POL processes intensity. Concentrations of primary and tertiary POL products - diene conjugates (DC) and malondialdehyde (MDA) - in the studied fibres (liver and kidney) were also investigated as compared with control.

Finding the concentration of malondialdehyde MDA was carried out according to the method described in the work [30]. The concentration of TBA-products was calculated according to the procedure described in the article [31]. Finding the concentration of DC (diene conjugates) in fibre homogenates and red cells hemolysate was carried out according to the procedure described in the article [32].

It was shown that the application of these preparations truly reduces the effects of oxidative stress, POL processes and,thus, proves its anti-inflammatory action.

It was of considerable interest to assess the interconnection between anti-inflammatory activity of the studied compounds and their chemical structure. DHQ derivatives in their structure present a system of phenolic residuals connected with various substitutes. Phenolic ring, owing to the system of conjugated dibonds, freely transfers electrons to free radicals, turning into phenoxyradical which is stable enough and does not participate in the further continuation of the chain. It is well known that a considerable antioxidant 
activity is characteristic of sterically hindered phenols which mainly react with radicals ROO and interrupt the chain of oxidation.

The structure of O-acyl radicals, as well as the character of para-substitute, is fundamental for antioxidant activity. The introduction into para-position of sterically hindered phenols of electron-donor substitutes increases their antioxidant activity, while the introduction of electron-acceptor substitutes reduces it.

Thus, in case with pentanicotinate of dihydroquercetin we can assume that its high antioxidant activity is explained by electron shift from central rings to peripheral due to their having links with nitrogen.

So, the use of acid chlorides of aromatic carboxylic acids, containing electron-accepting substitutes, as acetylizing agents makes it possible to obtain DHQ complex ethers and considerably improve their pharmacodynamics in biological tests.

\subsection{Biological Activity of Phosphorylated Dihydroquercetin Derivatives}

It is a well-known fact that phosphorylation of natural compounds such as carbohydrates, lipids, nucleosides results in enhancing and widening of their biological activity spectrum, which includes their antiproliferative action [33]. That is why we used DHQ phosphorylation to obtain compounds with cytotoxic antitumour activity.

Unfortunately, no reliable data about the ability of non-modified DHQ to effect the growth of tumour cells are presented in scientific literature. That is why we synthesized the compounds in which the molecule of native DHQ was used as a carrier of active cytotoxic phosphorus-containing pharmacophore groups.

The analysis of cytotoxic effect of a number of phosphorus-containing DHQ derivatives [34] was carried out in the Russian Oncological Center after N.N.Blohin (Moscow): 7-neopentylenethionphosphate (20a), 7-neopentyleneselenphosphate (20b), 7-diethylamidethylthionphosphate

(16a),

7-diethylamidethylselennphosphate

7-tetraethyldiamidethionphosphate

7-tetraethyldiamideselenphosphate

(14a),

7-dipiperidylthionphosphate

(13b),

and

7-dipiperidylselenphosphate (14b).

As an object of our investigation we used human tumour cells-ovarian carcinoma $\mathrm{CaOv}$ and T-lymphoma Jurkat. Cell cultures were grown in RPMI 1640 medium which contained $10 \%$ of calf embryotic serum.

Cytotoxic activity of the preparations was assessed by the ability of the compounds to inhibit the growth of tumour cells. The impact on the growth of tumour cells was assessed with the help of standard MTT test using the MTT reagent (3,4,5-dimethylthiazole-2-yl-2,5-dipheniltetrazolium bromide). The compound was considered active if the concentration 100 microns caused cell growth inhibition no less than 50\%. Measurement error was no more than 5\%. Active compounds were investigated on the experimental mice tumours in vivo.

Antitumour activity was assessed in vivo on transplantable tumours of hybrid-mice of the first generation $\mathrm{BDF}_{1}$, the mass being $18-25 \mathrm{~g}$. Transplantable tumours rank among obligatory models of animal tumours, which are used in selecting new anti-tumour substances - lymphocytic leukemia P-388, adenocarcinoma $\mathrm{Ca}-755$ and lung epidermoid carcinoma Lewis (LCC).

Antitumour effect was assessed by inhibition of tumour growth (TGI) and by the increase of life time of the treated animals (ILT). The minimal criteria of activity LCC $\geq 50 \%$, ILT $\geq 25 \%$.

Toxicity of the preparations was assessed by early death of mice as compared with the death of control animals and by the state of animal internals (lien, lungs, presence of metastases in lungs), by the change in the body mass in relation to the initial mass. 7-diethylamidethylthionphosphate (16a) was dissolved in DMSO and diluted with physiological solution for 
the concentration of DMSO to be no more than $10 \%$. The compound was introduced daily abdominally during 5 days in doses of $10 \mathrm{mg} / \mathrm{kg}, 25 \mathrm{mg} / \mathrm{kg}, 50 \mathrm{mg} / \mathrm{kg}$, $75 \mathrm{mg} / \mathrm{kg}, \quad 100 \mathrm{mg} / \mathrm{kg}, \quad 125 \mathrm{mg} / \mathrm{kg}$, and $150 \mathrm{mg} / \mathrm{kg}$. Treatment began in 48 hours after transplantation of solid tumours (Ca-755 and LCC) and in 24 hours after transplantation of P-388.

The results given in Tables 4 and 5 show that 7-diethylamidethylthionphosphate of dihydroquercetin in concentration 100 microns inhibited the growth of cells in lines $\mathrm{CaOv}$ and Jurkat by $83.9 \%$ and $84.8 \%$, correspondingly. $\mathrm{IC}_{50}$ in both cases was 50 microns.

Further the compound was recommended for studying antitumour activity in vivo. Studying antitumour activity of the compound on P-388 we found out that the preparation (when introduced in doses from 10 to $100 \mathrm{mg} / \mathrm{kg}$ ) had no antitumour effect, that is, it did not cause ILT.

Antitumour activity of the compound was also studied on Ca-755 in a wide range of doses from 25 $\mathrm{mg} / \mathrm{kg} \quad$ to $\quad 125 \quad \mathrm{mg} / \mathrm{kg}$. 7-diethylamidethylthionphosphate of dihydroquercetin was not effective in doses 25,50 , and $75 \mathrm{mg} / \mathrm{kg}$. At the same time the compound in doses $100 \mathrm{mg} / \mathrm{kg}$ and 125 $\mathrm{mg} / \mathrm{kg}$ had a moderate antitumour activity immediately after the end of daily abdominal introduction during 5 days: $\mathrm{TGI}=51 \%$ and $\mathrm{TGI}=57 \%$, correspondingly .
A high therapeutic effect of the studied substance was detected on LCC, it depended on the introduced dose of the compound. The compound manifested the highest inhibition of LCC growth in doses $75 \mathrm{mg} / \mathrm{kg}$ and $100 \mathrm{mg} / \mathrm{kg}$ : TGI $=89 \%$ and $88 \%$, correspondingly, after the end of the introduction. This high therapeutic effect lasted for 10 days: $74 \%$ and $68 \%$, correspondingly.

Besides, the compound showed antimetastatic effect. However, a statistically significant antimetastatic effect the compound showed only in doses $25 \mathrm{mg} / \mathrm{kg}$ and metastases growth inhibition was $37 \%$.

It was also found that 7-diethylamidethylthionphosphate of dihydroquercetin (16a) has low toxicity in therapeutic dose 75-100 $\mathrm{mg} / \mathrm{kg}$. $\quad \mathrm{LD}_{50}$ for male mice introduced daily abdominally during 5 days was $150 \mathrm{mg} / \mathrm{kg}$.

The above-enumerated results of the investigation show that the activity in reference to human ovarian carcinoma cells $\mathrm{CaOv}$ was detected in thionphosphates, which have in their composition the link P-N; the cytotoxic effect of selenonphosphates of a similar nature is a bit lower (at the same time their $\mathrm{IC}_{50}$ is much higher) or absent at all. With atoms of oxygen in place of atoms of nitrogen, sulfur (selenium), as well as atoms of carbon in place of atoms of nitrogen, the cytotoxic activity of the compounds was, unfortunately, not detected.

Table 4 Cytotoxic effect of DHQ derivatives in concentration 100 microns on the cells of the line CaOv in vitro.

\begin{tabular}{lll}
\hline Chemical compound & Cells proliferation inhibition (IC), \% & IC $_{50}$, microns $^{-}$ \\
\hline Dihydroquercetin (1) & 0 & 50 \\
7-Diethylamidethylthionphosphate of dihydroquercetin (16a) & 83.9 & 50 \\
7-Tetraethyldiamidethionphosphate of dihydroquercetin (13a) & 85.3 & 60 \\
7-Tetraethyldiamideselenphosphate of dihydroquercetin (14a) & 79.2 & 65 \\
7-Dipiperidylthionphosphate of dihydroquercetin (13b) & 76.3 & 70 \\
7-Dipiperidylselenphosphate of dihydroquercetin (14b) & 77.0 & \\
\hline
\end{tabular}

Table 5 Cytotoxic effect of DHQ derivatives in concentration 100 microns on T-lymphoma cells of the line Jurkat in vitro.

\begin{tabular}{lll}
\hline Chemical compound & Inhibition of cell proliferation (IC), \% & IC $_{50}$, microns \\
\hline Dihydroquercetin (1) & 0 & - \\
7-neopentylenethionphosphate of dihydroquercetin (20a), & 16,3 & $>>100$ \\
7-neopentyleneselenphosphate of dihydroquercetin (20b), & 16,3 & $>>100$ \\
7-Diethylamidethylthionphosphate of dihydroquercetin (16a) & 84,8 & 50 \\
7-diethylamidethylselennphosphate of dihydroquercetin (17a), & 66,9 & 50 \\
\hline
\end{tabular}


Thus, it was found that 7-diethylamidethylthionphosphate of dihydroquercetin (16a) is a new inventive compound with antitumour effect on some transplantable solid tumours of mice with low toxicity. It also has an antimetastatic activity.

\subsection{Biological Activity of Aminomethylated Dihydroquercetin Derivatives}

It was shown that 6-isopropylaminemethyldihydroquercetin has an actprotecting activity. It was also found out that the obtained derivatives considerably increase antioxidant properties of DHQ [35, 36].

Summing up it should be noted that due to chemical modification of DHQ the spectrum of this unique flavonoid biological activity is significantly expanded.

\section{Conclusions}

The procedure of obtaining water-soluble dihydroquercetin was worked out. A number of new totally acidylated derivatives of dihydroquercetin were synthesized. Selective phosphorylation of dihydroquercetin by trivalent phosphorus acids amides was studied. The possibility of mono- and bi-aminomethylation was shown. Biological activity of chemically modified dihydroquercetin derivatives was analyzed.

\section{References}

[1] Pew, J. C. 1948. "A Flavonone From Douglas-Fir Heartwood.” J. Am. Chem. Soc. 70 (9): 3031-4.

[2] Kurth, E. F., and Chan, F. L. 1953. "Extraction of Tannin and Dihydroquercetin from Douglas-Fir Bark." J. Am. Leather Chem. Assoc. 48 (1): 20-32.

[3] Habtemariam, S. 1997. "Flavonoids as Inhibitors or Enhancers of the Cytotoxicity of Tumor Necrosis Factor-Alpha in L-929 Tumor Cells." J. Nat. Prod. 60 (8): 775-8.

[4] Haraguchi, H., Ohmi, I., Fukuda, A., Tamura, Y., Mizutani, K., Tanaka, O., and Chou, W. H. 1997. "Inhibition of Aldose Reductase and Sorbitol Accumulation by Astilbin and Taxifolin Dihydroflavonols in Engelhardtia Chrysolepis." Biosci. Biotechnol. Biochem. 61 (4): 651-4.
[5] Kolhir, V. K., Tyukavkina, N. A., and Bykov, V. A. 1995. "Dihydroquercetin - a New Antioxidant and Capillary Protective Agent." Chem.-Pharm. J. 29 (9): 61-4. (in Russian)

[6] Teselkin, Y. O., Zhambalova, B. A., Babenkova, I. V., and Tyukavkina, N. A. 1996. "Antioxidant Properties of Dihydroquercetin.” Biofizika 41 (3): 620-4. (in Russian)

[7] Igarashi, K., Uchida, Y., Murakami, N., Mizutani, K., and Masuda, H. 1996. "Effect of Astilbin in Tea Processed from Leaves of Engelhardtia Chrysolepis on the Serum and Liver Lipid Concentrations and On the Erythrocyte and Liver Antioxidative Enzyme Activities of Rats." Biosci. Biotechnol. Biochem. 60 (3): 513-5.

[8] Chu, S. C., Hsieh, Y. S., and Lin, J. Y. 1992. "Inhibitory Effects of Flavonoids on Moloney Murine Leukemia Virus Reverse Transcriptase Activity." J. Nat. Prod. 55 (2): 179-83.

[9] Huang, M. T., Chang, R. L., Wood, A. W., Newmark, H. L., Sayer, J. M., Yagi, H., Jerina, D. M., and Conney, A. H. 1985. "Inhibition of Mutagenicity of Bay-Region Diol-Epoxides of Polycyclic Aromatic Hydrocarbons by Tannic Acid, Hydroxylated Anthraquinones and Hydroxylated Cinnamic Acid Derivatives." Carcinogenesis 6 (2): 237-42..

[10] Il'iuchenok, T. Iu., Khomenko, A. I., Frigidova, L. M., Lepekhin, V. P., and Verkhovskii, Iu. G. 1975. "Pharmacological and Radioprotective Properties of Some Gamma-Pyrone Derivatives (Flavanones and Flavanols)." Farmakol. Toksicol. 38 (5): 607-12. (in Russian)

[11] Bronner, C., and Landry, Y. 1985. "Kinetics of the Inhibitory Effect of Flavonoids on Histamine Secretion from Mast Cells." Agents Actions 16 (3-4): 147-51.

[12] Schwartz, A., and Middleton, E. Jr. 1984. "Comparison of the Effects of Quercetin with Those of Other Flavonoids on the Generation and Effector Function of Cytotoxic T-Lymphocytes.” Immunopharmacology 7 (2): 115-26.

[13] Vladutiu, G. D., and Middleton, E. Jr. 1986. "Effects of Flavonoids on Enzyme Secretion and Endocytosis in Normal and Mucolipidosis Fibroblasts." Life Sci. 39 (8): 717-26.

[14] Cechinel-Filho, V., Vaz, Z. R., Zunino, L., Calixto, J. B., and Yunes, R. A. 2000. "Antinociceptive and Anti-Oedematogenic Properties of Astilbin, Taxifolin and Some Related Compounds." Arzneimittelforschung 50 (3): 281-5.

[15] Jurado, J., Alejandre-Durán, E., Alonso-Moraga, A., and Pueyo, C. 1991. "Study on the Mutagenic Activity of 13 Bioflavonoids with the Salmonella Ara Test." Mutagenesis 6 (4): 289-95.

[16] Solimani, R. 1996. "Quercetin and DNA in Solution: Analysis of the Dynamics of Their Interaction with a Linear Dichroism Study.” Int. J. Biol. Macromol. 18 (4): 
287-95.

[17] Biziagos, E., Crance, J. M., Passagot, J., and Deloince, R. 1987. "Effect of Antiviral Substances on Hepatitis A Virus Replication in Vitro.” J. Med. Virol. 22 (1): 57-66.

[18] Nifant'ev, E. E., Koroteev, M. P., Kaziev, G. Z., and Uminskiy, A. A. 2002. Method for separating dihydroquercetin. RF Patent 6153271, filed April 13, 2000, and issued May 15, 2002. (in Russian)

[19] Nifant'ev, E. E., Koroteev, M. P., Kaziev, G. Z., and Kukhareva, T. S. 2004. Method for compex larchwood treatment. RF Patent 2233858, filed August 4, 2002, and issued August 10, 2004. (in Russian)

[20] Koroteev, A. M., Kaziev, G. Z., Koroteev, M. P., Nifant'ev, E. E., and Shutov, V. M. 2010. Water-soluble complex compound of inclusion dihydroquercetin- $\beta$-cuclodextrin and the method for its synthesis. RF Patent 2396077, filed April 27, 2009, and issued August 10, 2010. (in Russian)

[21] Aft, H. 1961. "Chemistry of Dihydroquercetin. I. Acetate Derivatives.” J. Org. Chem. 26 (6): 1958-63.

[22] Agrawal, P. K. 1989. Carbon-13 NMR of Flavonoids. Amsterdam: Elsevier.

[23] Kiehlmann, E., Biradha, K., Domasevitch, K. V., and Zaworotko M. J. 1999. "Crystal structures of Dihydroquercetin 3-Acetate and Dihydroquercetin 3,3',4',7-Tetraacetate: Hydrogen Bonding in 5-Hydroxyflavanones." Can. J. Chem. 77 (8): 1436-43.

[24] Nifant'ev, E. E., Krymchak, M. S., Koroteev, M. P., Koroteev, A. M., Kukhareva, T. S., and Vasyanina, L. K. 2011. "Exhaustive Acylation of Dihydroquercetin." J.. Gen. Chem. 81 (1): 106-9. (in Russian)

[25] Nifant'ev, E. E., Kukhareva, T. S., Dzgoeva, Z. M., Vasyanina, L. K., Koroteev, M. P., and Kaziev G. Z. 2003. "Selective Phosphorylation of Dihydroquercetin with Trivalent Phosphorus Reagents." Heteroatom Chemistry 14 (5): 399-403.

[26] Sergievich, A. A., Batalova, T. A., Plastinin, M. L., Koroteev, M. P., Koroteev, A. M., Kukhareva, T. S., and Nifant'ev, E. E. 2011. "Actprotecting and Neurotropic Effects of a New Dihydroquercetin Derivative." Newsletter of New Med. Technologies. XVIII (2): P.77-80. (in Russian)

[27] Rogovskiy, V. S., Matiushin, A. I., Shimanovski1̌, N. L.,
Semeǐkin, A. V., Kukhareva, T. S., Koroteev, A. M., Koroteev, M. P., and Nifant'ev, E. E. 2010. "Antiproliferative and Antioxidant Activity of New Dihydroquercetin Derivatives." Experim. and Clinical Pharmacology 73 (9): 39-42. (in Russian)

[28] Habriev, R. U. 2005. Guide to Experimental (Preclinical) Study of New Pharmacological Substances. Moscow: Medicina.

[29] Kazakov, V. P. 1980. Chemiluminescence of Uranyl, Lanthanoids and Other Elements. Moscow: Nauka.

[30] Uchiyama, M., and Mihara, M. 1978. "Determination of Malonaldehyde Precursor in Tissues by Thiobarbituric Acid Test." Anal. Biochem. 86 (1): 271-80.

[31] Gavrilov, V. B., Gavrilova, A. R., and Mazhul', L. M. 1987. "Methods of Determining Lipid Peroxidation Products in the Serum Using a Thiobarbituric Acid Test." Aspects of Med. Chemistry 33 (1): 116-22.

[32] Stal'naya, T. A. 1972. Method of Defining Diene Conjugation of Unsaturated High Fatty Acids. Mod. Methods in Biochemistry. Moscow: Medicina.

[33] Zinchenko, V. P., Koroteev, M. P., Nifant'ev, E. E., Kochetkov, N. K. 1987. "Reduction Effect of Calcium Ions Ph-Stimulated with Mitogens of Thymocytes with Carbohydrate Amidophophates Acting." Rep. AS USSR 297 (7): 1482-90. (in Russian)

[34] Nifant'ev, E. E., Koroteev, M. P., Kaziev, G. Z., Kukhareva, T. S., Zhukova, O. C., and Smirnova, Z. S. 2009. Agent with antitumour activity and the method of its synthesis. RF Patent 2349317, filed July 30, 2007, and issued March 20, 2009. (in Russian)

[35] Sergievich, A. A., Batalova, T. A., Dorovskih, V. A., Plastinin, M. L., Nifant'ev, E. E., Sleptsova, L. S., Koroteev, M. P., and Koroteev, A. M. 2009. Method of normal microbial flora formulation correction in experiment. RF Patent 2366418, filed September April 09, 2008, and issued September 10, 2009. (in Russian)

[36] Batalova, T. A., Dorovskih, V. A., Sergievich, A. A., Plastinin, M. L., Koroteev, M. P., Koroteev, A. M., and Nifant'ev. E. E. 2009. Method of increasing the level of working efficiency in laboratory animals in experiment. RF Patent 2371175, filed September 14, 2007, and issued October 27, 2009. (in Russian) 